\title{
Bond University
}

\section{Legal Education Review}

Volume $31 \quad$ Issue 1

2021

Academics Embrace Disruption: Lessons Learned Teaching First Year Law During a Pandemic

Kathleen Raponi

Victoria University

Gayani Samarawickrema

Victoria University

Gerard Everett

Victoria University

Lloyd England

Victoria University

Tristan Galloway

Victoria University

Follow this and additional works at: https://ler.scholasticahq.com/

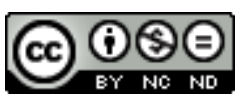

This work is licensed under a Creative Commons Attribution-Noncommercial-No Derivative Works 4.0

Licence. 


\title{
ACADEMICS EMBRACE DISRUPTION: LESSONS LEARNED TEACHING FIRST YEAR LAW DURING A PANDEMIC
}

\author{
KATHLEEN RAPONI, "GAYANI SAMARAWICKREMA, ${ }^{* *}$ \\ GERARD EvERETT, ${ }^{*}$ LlOYd ENGLAND, ${ }^{*}$ Tristan GALlOWAY ${ }^{+}$
}

\section{INTRODUCTION}

In March 2020, Victoria University (VU) Australia, like many higher education institutions the world over, responded to the global COVID-19 pandemic by closing its campuses and delivering all units and course work remotely and online. ${ }^{1}$ Confronted with an unknown, rapidly advancing pandemic and the terrifying impetus to socially isolate, the transition to remote online learning ${ }^{2}$ occurred within a week with correspondingly limited consideration of online pedagogy, assessment, learning and teaching. Academics frantically scrambled to move content and resources online and agonised about transforming their face-to-face teaching and laboratory sessions to a virtual space or replacing traditional exams with viable online alternatives. VU was no different in this mad rush.

Since 2018, all VU Bachelor's degrees have been delivered via 'Block' mode, an intensive study approach requiring students to undertake one unit (subject) at a time (sequentially instead of concurrently) over a four-week period. This Block mode consists of up to three face-to-face sessions per week complemented by a robust active online learning space called VU Collaborate, the university's learning management system (LMS). ${ }^{3}$ This LMS provides all unit resources, learning activities and scaffolded formative and summative assessments. Consequently, as the pandemic unfolded and staff and students isolated, VU students already had an established, dynamic

* First Year College Law, Victoria University

** Connected Learning, Victoria University

$+\quad$ College of Law \& Justice, Victoria University

1 'Coronavirus disease (COVID-19) pandemic', World Health Organisation (Webpage, 2020) <https://www.who.int/emergencies/diseases/novel-coronavirus2019>.

2 Lee, Kyungmee 'Coronavirus: universities are shifting classes online - but it's not as easy as it sounds', The Conversation (online, 10 March 2020) $<$ https://theconversation.com/coronavirus-universities-are-shifting-classes-onlinebut-its-not-as-easy-as-it-sounds-133030>.

3 Trish McCluskey et al, 'Building on the VU Block Foundations: Results from the Inaugural First Year Cohort' (2020) 42 Research and Development in Higher Education 61. 
online learning space for each of their units. These highly learnerfocused spaces collaboratively designed with specialist academics, learning designers, librarians and supporting professionals ensured accessible learning resources; clear statements of expectations, aims and learning outcomes; details of assessment tasks, criteria, requirements, online Dropbox submissions and feedback processes. The learning space also outlined participation expectations, forums that provided support and information to student questions including a dedicated, single location for important news and announcements. These learning spaces align with the national Technology Enhanced Learning Accreditation Standards (TELAS) ${ }^{4}$ and were already in use when the pandemic struck.

This enabled VU academics to extend to pandemic-precipitated remote teaching from a solid base that embedded well-known online learning strategies, although transitioning their classroom teaching to synchronous online teaching via Zoom (a cloud-based video conferencing app integrated within the LMS overnight to support VU's remote teaching) was a totally new experience. Some academics also trailed a combination of synchronous online zoom teaching together with asynchronous activities such as short videos and discussion board activities. Nevertheless, both academics and learners were familiar with the LMS and the hybrid blended learning environment of the Block.

Higher education institutions using online technology at a time of crisis is not new. ${ }^{5}$ The comprehensive national study undertaken by the Australian government across the entire higher education sector in Australia during the COVID-19 pandemic identified a range of areas including strategies that worked well and the issues that needed to be addressed, offering a sound basis for this investigation. ${ }^{6}$ Focusing on a single discipline, recent studies have also examined how the pandemic precipitated a shift online in teaching undergraduate law. ${ }^{7}$

This study differs in its empirical focus on both the first-year law student experience, and the use of intensive delivery, during the pandemic. Specifically, the study evaluates the teaching practices adopted for online and remote Block delivery of first year law units during the initial two Blocks of the COVID-19 pandemic. It focuses on the delivery effectiveness of nine first year Law and Justice units that

4 Dominique Parrish, Allen Christie, and Chris Campbell, 'Teaching on-line -what students want' Campus morning mail (online, 5 April 2020) $<$ https://campusmorningmail.com.au/news/teaching-on-line-what-studentswant/?utm_campaign $=$ website\&utm_source $=$ sendgrid.com\&utm_medium $=$ email\#s endgrid_mc_email_subscribe>.

5 Peggy $\overline{\mathrm{C}}$ Holzweiss et al, 'Crisis Planning for Online Students: Lessons Learned from a Major Disruption’ (2020) 24(2) Online Learning 22-37.

6 Australian Government Tertiary Education Quality and Standards Agency, Foundations for good practice: The student experience of online learning in Australian higher education during the COVID-19 pandemic (Report, November 2020) <https://www.teqsa.gov.au/latest-news/publications/foundations-goodpractice-student-experience-online-learning-australian $>$.

7 Bridget J Crawford and Michelle Simon, 'Law Faculty Experiences Teaching During the Pandemic' (2020) St. Louis University Law Journal (forthcoming). 
had already been designed for blended learning via the LMS in intensive Block mode.

\section{METHOD}

The study focused on six academics who taught the nine first year law units undertaken as part of the Law and Justice degrees, specifically during two iterations of Block delivery (Blocks 2 and 3 of Semester 1, 2020) when the hurried shift to online learning occurred. These units were Australian Legal System in Context, Legal Research Methods, Legal Interpretation, Contract Law, Torts, Introduction to Criminology, Policing and Offending, Criminal Law, Criminal Investigation, and Sentencing and Procedure. Participant selection therefore was targeted and only included the six academics in the First Year Law program who revised and taught those units remotely online during Blocks 2 and 3 of Semester 1, 2020, at the commencement of the global pandemic.

Data was collected via two focus group interviews (conducted via Webex) to obtain an up-close, in-depth and personal perspective of the shift to remote, online teaching. To remove any bias, the interviews were intentionally facilitated by a teaching and learning academic who did not design or teach the units in the study. The entire population was interviewed excepting one who responded to the interview questions via email. As such, there were no non-responses. Interviewee comments and observations were based on the breadth of teaching across the nine revised units delivered in Block 2 and Block 3, Semester 12020 (30 March 2020-1 May 2020) to a total of 997 students (see Table 1). The study had the approval of VU's Human Research Ethics Committee (HRE17-192). 
Table 1

Law units offered during Block 2 and Block 3 and student enrolment numbers. 8

\begin{tabular}{|c|c|c|c|c|c|c|c|c|c|}
\hline 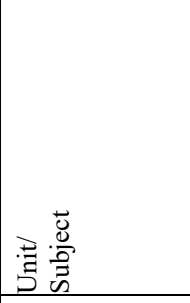 & 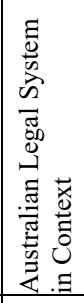 & 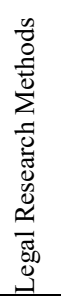 & 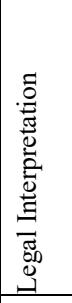 & 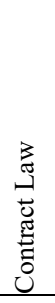 & : & 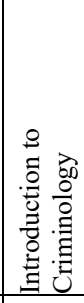 & 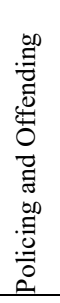 & 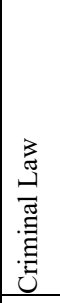 & 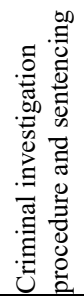 \\
\hline $\begin{array}{l}\text { No. of blocks } \\
\text { taught online } \\
\text { and remotely }\end{array}$ & 2 & 2 & 1 & 1 & 1 & 1 & 2 & 1 & 1 \\
\hline $\begin{array}{l}\text { No. of students } \\
\text { who attempted } \\
\text { the unit in } \\
\text { Block } 2 \text { ( } 30 \\
\text { March-1 May } \\
2020)\end{array}$ & 101 & 163 & 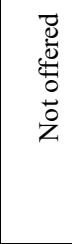 & 82 & 36 & 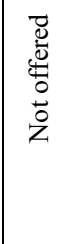 & 66 & 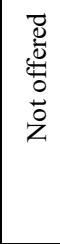 & 39 \\
\hline $\begin{array}{l}\text { No of students } \\
\text { who attempted } \\
\text { the unit in } \\
\text { Block } 3 \text { (4 } \\
\text { May -29 May } \\
2020)\end{array}$ & 96 & 58 & 106 & 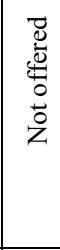 & 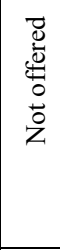 & 43 & 71 & 116 & 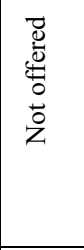 \\
\hline Total & 197 & 221 & 106 & 82 & 36 & 43 & 137 & 116 & 39 \\
\hline
\end{tabular}

\section{PROCESS}

All authors individually read through the entire data set and became familiar with the information before any thematic analysis. Themes were discussed to ensure that they reflected the qualitative data, then were considered from a SWOT lens ascribing the theme to strengths, weaknesses, opportunities and threats (Table 2). The SWOT Analysis developed in the 1960s offered organisations a framework to assess their current position and develop strategic plans for their future. ${ }^{9}$ The framework evaluates the organisation's internal and external environments through identifying the strengths, weaknesses, opportunities and threats, designed to maximize the positive aspects (the strengths and opportunities) and to adopt measures to minimise negative impacts (arising from the weaknesses and threats) in the future. ${ }^{10}$ SWOT analysis has previously been adapted by business

8 Victoria University, 'Pass Rates' (Webpage, 8 September 2020) $<$ https://infovu2.vu.edu.au $>$.

9 Carly Probet, The SWOT Analysis: A Key Tool for developing your business strategy (Lemaitre Publishing, 2015) 4.

10 Ibid 5. 
academics to examine their transitioning to online teaching. ${ }^{11}$ More recently, SWOT analysis has been used in the UK and Ireland to analyse the online adaptations of anatomical education in response to the COVID-19 pandemic ${ }^{12}$ and similarly at the Lebanese International University in their evaluation of their quick shift from classroom to online teaching of Chemistry, also in response to COVID-19. ${ }^{13}$

This evaluation of the impact of the move to remote delivery similarly employs the SWOT lens and was therefore guided by the following four descriptors:

Strengths - Factors that are likely to have a positive/enabler effect on achieving the learning and teaching aims in remote Block delivery of first year Law units;

Weaknesses - Factors that are likely to have a negative/barrier effect on achieving the learning and teaching aims in remote Block delivery of first year Law units;

Opportunities - External Factors that are likely to have a positive effect on meeting/exceeding learning and teaching aims not previously considered, in remote Block delivery of first year Law units; and

Threats - External Factors and conditions that are likely to harm achieving learning and teaching aims or making the aims redundant or unachievable in remote Block delivery of first year Law units.

Once the data was categorised according to SWOT principles, it was then analysed by themes in relation to factors that impact on student engagement by drawing on Moore's transactional distance theory. ${ }^{14}$ According to Moore, the distance between learner and teacher termed 'transactional distance' is not geographical but pedagogical. Transactional distance is relative and is an interplay between three distinct elements: dialogue (between teacher + learner and learner + learner), structure (being the learning design of content and the learning environment) and learner autonomy (the extent of learner independence). Benson and Samarawickrema, drawing on Moore's transactional distance theory, demonstrate the impact of dialogue, structure and learner autonomy on e-learning contexts and how transactional distance can be increased or reduced through structure and dialogue. ${ }^{15}$ As such, the study used dialogue, structure and learner

11 Esmeralda de los Santos and Nursen Zanca, 'Transitioning to online: A SWOT analysis by first time online business faculty' (2018) 12(3) e-Journal of Business Education \& Scholarship of Teaching 69.

12 Georga Longhurst et al, 'Strength, weakness, opportunity, threat (SWOT) analysis of the adaptations to anatomical education in the United Kingdom and Republic of Ireland in response to the Covid-19 pandemic' (2020) 13(3) Anatomical Sciences Education 298.

13 Kassem Hallal, Hassan HajjHussein, and Sami Tlais 'A quick shift from classroom to Google classroom: SWOT analysis' (2020) 97(9) Journal of Chemical Education, 2806-2809.

14 Moore, Michael, 'Theory of Transactional Distance' in Desmond Keegan (ed), Theoretical Principles of Distance Education (London Routledge, 1997) 22-38.

15 Robyn Benson and Gayani Samarawickrema, 'Addressing the Context of ELearning: Using Transactional Distance Theory to Inform Design’ (2009) 30(1) Distance Education 5-21. 
autonomy as an additional analytical lens to further tailor the SWOT Analysis to educational outcomes.

\section{FINDINGS}

The study findings are presented in a SWOT framework and summarised in Table 2. They indicate that the Block had its strengths in online remote delivery. While the LMS in each unit with all readings, links to resources, scaffolded learning activities, structured interactions with clear instructions and online assessment submission and feedback were the greatest asset, it also offered opportunities that were both practical and unexpected.

Although the Block mode gave the study participants a strong footing to commence their remote teaching, the key weakness was the loss of face-to-face contact, now replaced by Zoom. This posed threats related to learning. 
Table 2

SWOT Analysis Table: Summary of Strengths, Weaknesses, Opportunities and Threats

\section{Strengths}

Dialogue

- Structured and regular communication - live Zoom sessions as per timetable

- Increased attendance

- $\quad$ More time effective

- Breakout rooms facilitated group discussions

- Zoom cameras on

- Increased engagement

Structure

- $\quad$ Pre-existing learning materials adapted for online delivery

- $\quad$ Reduced number of activities.

- Assessment style retained Learner Autonomy

- Asynchronous and synchronous material

- $\quad$ Students adapted to Zoom

\section{Opportunities}

Dialogue

- More time-effective

- Use of Zoom and breakout rooms

- Regular academic meetings/touchpoints

Structure

- Zoom training for academics

- Formalised academic peer support and collaboration

- Block model creates an opportunity to evaluate and develop

- Used essential content only

Learner Autonomy

- Greater attendance, participation and completion of unit

- Restrictions and lockdown commitment to studies

- Students reduced travel time

\section{Weaknesses}

Dialogue

- Students who did not participate in Zoom breakout room activities

- Limited access to technology

- $\quad$ Reduced personal element and missing instant feedback online

- Lack of social interaction between staff

- Zoom cameras off

Structure

- Limited time to prepare for online delivery

- Rearrange timings / mode of some activities

- All assessments online only

Learner Autonomy

- Increased email queries

- Loss of library services

- Reduced class control

\section{Threats}

Dialogue

- Student online/remote distractions

- Zoom camera used to confirm engagement

- $\quad$ Poor teacher feedback with non-camera users

Structure

- $\quad$ Academic fatigue keeping engagement

Learner Autonomy

- Commitment to study in Block mode

- Technical issues or access to technology/internet 


\section{A Strengths}

Dialogue: Remote delivery replaced the timetabled face-to-face class with a Zoom meeting, providing regular structured opportunities for teacher and student dialogues. An academic was the first person to $\log$ into the Zoom meeting and the last to log off, maintaining an open line of communication and opportunities for students to ask questions and mirroring the face-to-face class structure. Participants were unanimous that timetabled synchronous, online remote delivery increased general attendance, when compared to face-to-face delivery. Also they agreed that learner engagement was strengthened through learner + learner dialogue, promoted through extensive use of group work via Zoom 'breakout rooms' feature, creating smaller virtual rooms for students to collaborate, away from the large class setting. Similarly, participants pointed out a greater sense of connection and improved dialogue with those students who have their Zoom camera on, indicating better teacher + learner rapport.

Structure: All participants agreed that the greatest strength of the Block in remote delivery was its structured (weekly, session by session activities with supporting resources) space on VU Collaborate. This online space required no major changes in the sudden transformation to remote learning although some participants reduced the number of activities. The existing assessment structure was also able to be maintained.

Learner autonomy: The VU Collaborate space with all the learning resources called for independent learning through asynchronous interactions. As participants pointed out, both the structure of the learning space and the in-built dialogue (between teacher + learner and learner + learner) within the unit contributed to fostering learner autonomy. The scheduled Zoom interactions served to complement and build upon this autonomous learning.

\section{B Weaknesses}

Dialogue: Participants noted that a small number of students did not participate in the Zoom breakout room activities, missing out on the learner + learner dialogue. Students attending with their Zoom camera off affected the teacher's ability to build a stronger teacher + learner connection which in turn reduced the interaction and directly impacted on the teacher's ability to respond to non-verbal cues. Technology issues and limited internet access also negatively impacted dialogue and participation. Participants recognised the criticality of dialogue and the challenge of maintaining student attention and engagement in a live Zoom session for three hours and commented, '[T]he first time I felt I needed to keep them entertained for the whole three hours...' (Participant 5), leading some participants to extend the use of resources to include YouTube videos.

Structure: Participants used the existing VU Collaborate space with minimum consideration of its appropriateness for remote online learning. While some activities were rescheduled and in-class 
assessments were moved online, there was minimal time to consider the changes in relation to structural cohesiveness.

Learner autonomy: Participants observed an increase in email queries from students indicating a greater need for general help. Overall, students seemed to need more support in all areas including the use of the library and technical support from IT. In an attempt to control the increasing volume of emails, one (Participant 5) modified his strategy by getting students to ask the questions in class.

\section{Opportunities}

Dialogue: Synchronous dialogue via Zoom eliminated travel to the university and was an opportunity that facilitated learner + learner dialogue and learner + teacher dialogue in a time-effective manner. Zoom breakout rooms in small groups fostered learner + learner connections in a time of isolation, an unintended opportunity. For the participants (who were also academics), the collaborative meetings, ongoing dialogue and touchpoints facilitated an ongoing professional dialogue resulting in sharing teaching approaches, digitally replacing on-campus collegiality; '...we have each other.'(Participant 5)

Structure: Participants, as academics, maintained structured regular meetings (also via Zoom) to discuss issues and share strategies related to teaching remotely in Block mode. These meetings were purposeful and offered structured professional development in using Zoom to facilitate learning, and other targeted support to implement the transition of online remote delivery. These regular collegial meetings evolved into a small informal learning community and they made improvements 'I changed the way I did things' (Participant 5) and demonstrated 'efficiency of teaching' (Participant 2) to become more effective.

Learner autonomy: Participants noted the key opportunity for their learners was the lockdown restrictions. Forced to stay at home, they noted a degree of increased learner independence - in terms of preparation, attendance, general participation, and completion of units by students. The pandemic restrictions presented students with the opportunity to focus on their studies without the distraction of other commitments as well as the time gained with the absence of travel to university. Forced to participate remotely, the online forum empowered students to raise queries and interact.

\section{Threats}

Dialogue: Participants noted that with the opportunities came threats, such as students' potential distractions whilst learning remotely online. One obvious threat in the Zoom environment was the '...lack of control for example, students going to make a coffee during class...' (Participant 2). These were easy temptations which threatened learner + learner dialogue and learner + teacher dialogue. Also, a significant potential threat to dialogue was when learners turned their Zoom camera off. Engagement with other learners or the teacher was 
sometimes non-existent in these circumstances, (such as when a student also failed to respond via their microphone, for example) resulting in teachers providing generalised feedback rather than targeted and specific feedback.

Also it was observed some '... students did not like remote learning because of [the] non-uni experience...' (Participant 4), as the remote learning precluded the learners from conversations and the complete on-campus student experience.

Structure: Considerations of construct and organisation of the learning and teaching were central to some respondents; 'From a personal perspective, I had to think more - what was I doing and how [I was] delivering...' (Participant 5). Indeed, this had an adverse aspect as most participants emphasised the demanding schedule they maintained in their attempts to provide a well-supported, wellstructured, rewarding learning experience to their students and warned of increased workload leading to potential teacher-fatigue as a genuine threat.

Learner autonomy: Participants agreed that in these isolated conditions, commitment and motivation to study was critical if students were to be successful. The absence of that motivation and commitment was identified as a serious threat. Students increasingly needed to be self-sufficient and independent. Correspondingly a critical threat was lack of access to technology and an internet connection with adequate bandwidth for Zoom - a factor that could be attributed to declining student engagement. One academic reported that some students 'experienced drop outs' and there were '...delays in IT responding to requests' (a reference to IT Helpdesk support) (Participant 3).

Overall, the study findings indicated that although the uniqueness of the Block offered some key strengths and opportunities in remote delivery, the situation also induced some weaknesses and threats that were brought to the fore. These findings are examined further using Moore's dialogue - structure - learner autonomy elements in his transactional distance theory ${ }^{16}$ in the discussion section below.

\section{DISCUSSION}

The SWOT analysis proved a useful tool to categorise the findings of the participant's teaching practices adopted for online and remote Block delivery. To further assess and interpret these findings, they were reviewed using Moore's transactional distance theory as a lens informing a discussion in relation to dialogue, structure and learner autonomy.

Dialogue: Moore advocated individualised communication and increased communication to reduce the teacher + learner and learner + learner gap. ${ }^{17}$ The findings indicated that dialogue as described by

16 Michael G. Moore, 'Editorial: Distance Education Theory' (1991) 5(3) American Journal of Distance Education 1-6.

17 Michael G Moore, 'Toward a Theory of Independent Learning and Teaching' (1973) 44 The Journal of Higher Education 661, 664-665. 
Moore was critical to student engagement and remote learning as was "structured [and] regular communication". ${ }^{18}$ Having students' Zoom cameras on, increased teacher + learner dialogue and increased the potential for learner + learner connections in Zoom breakout rooms. Considering students were already missing the on-campus university experience during the pandemic, the non-use of Zoom cameras potentially isolated learners, further reducing the possibility to foster learner + learner connections and disheartened the teacher who also missed the classroom experience and the 'humanity side of the classroom' (Participant 2). Another participant also shared this notion — 'I miss seeing my students ... I don't have a feeling of a job well done. Being in a room with students - really engaged, that's a job well done. I don't have that feeling anymore. I am not getting the interaction' (Participant 4). Although this non-participation via the Zoom camera of some learners could be attributed to technology/internet access or simply not wanting to publicise shared living spaces and home contexts, it was a significant weakness in intensive Block mode remote delivery, worthy of future study to better understand impacts.

Participants used Zoom breakout rooms by allocating students into groups and shuffling groups, thus allowing students to work with an array of students, in contrast to the on-campus classroom where students tended to habitually sit with and work within the same peer group. This deliberate facilitation by the teacher was a strength in intensive Block mode remote delivery as it fostered dialogue among those who would not have otherwise interacted, potentially removing social barriers which ordinarily exist in the physical classroom. Some participants highlighted the importance of stimulating interaction and the early use of the breakout rooms 'I tried to add value to the slides...' (Participant 2) to build learner + learner connection through dialogue and networking.

The findings highlight it could not be assumed that by providing opportunities for direct learner involvement (i.e. real-time chat, email, discussion boards, group discussions, debates, small group Zoom breakout rooms) that all learners will automatically and voluntarily use them. It was obvious these features that fostered dialogue and connection needed to be purposefully structured into the learning environment. In addition, clear support on how these should be used and the learning benefits need to be communicated upfront and made part of the dialogue.

Structure: Although some warn that face-to-face teaching methods cannot be mirrored in an online setting, ${ }^{19}$ Moore's transactional distance theory highlights the significance of structure as a central design attribute in online environments. ${ }^{20}$ Having an LMS that already

18 Charlene Dykman and Charles Davis, 'Online Education Forum: Part Two Teaching Online Versus Teaching Conventionally' (2008) 19(2) Journal of Information Systems Education 157, 160.

19 Corbin and Bugden 'Online Teaching: The Importance of Pedagogy, Place and Presence in Legal Education.' (2018) 28 Legal Education Review 1, 2.

20 David S. Stein et al, 'Bridging the Transactional Distance Gap in Online Learning Environments' (2005) 19(2) The American Journal of Distance Education 105-118. 
had all resources created for each session was a strong structured foundation to begin with. To this existing structure, the Zoom class was added and the structure further adapted for an online delivery.

Structured interactions via Zoom breakout rooms were introduced by most participants. A further fine tuning of structure had participants reducing and rationalising the number of practical activities. Participant 4 created a summarised document of key dates and times to help guide students, and participant 2 gave students a break every 55 minutes just as they would in an ordinary face-to-face classroom.

Two participants opted for shortened Zoom sessions, paired with post-Zoom learning activities. This modified structure allowed students time to apply their learning during the session to a post-class activity that needed to be posted on the discussion board, designed to promote deeper learning. ${ }^{21}$

Although there was consensus by the participants that once they had taught a unit online they became more confident, there were challenges to maintaining student engagement in the Zoom environment, leading to teacher fatigue. One participant admitted 'I miss the immediate feedback...' (Participant 5) of the in-person classroom, affecting their overall teaching satisfaction.

The participants self-evaluated their implementation of online delivery and made improvements to the delivery and structure. Some study participants stated they found making improvements easier after teaching one Block online and remotely as the first iteration helped to identify teaching approaches and learning materials which were more suitable for the purpose. For example, when the participation in the discussion board activities declined as the unit delivery progressed, one participant modified the structure by linking the discussion forum activity to an assessment task 'In block 3 offering [I] changed an assessment to include a reflection on the discussion board activities...this increased participation.' (Participant 1). This modified structure resulted in improved learner + learner dialogue. This agile, continuous structural improvement based on teacher reflections was made possible because the Block mode provides for multiple offerings over a semester period, a benefit of Block mode delivery, not so frequently available to offerings at semester-based tertiary institutions. Nonetheless, these findings underscore the requirement to further structure the online environment to facilitate successful learning intensively in the Block.

Derived from the study findings, a useful approach would be to improve the online space with a greater focus on teacher presence and a teacher voice to address decreasing student participation as the weeks and months in isolation persisted. Linking activities directly to assessment tasks would also promote greater participation, as would setting short term goals with clear explanations (eg reasons for setting a quiz at the start and why students need to complete it before addressing the next task), and assessment tasks that better suit online remote delivery. Also, structuring an effective classroom dialogue with

21 Corbin and Bugden (n19) 11. 
regular, higher order open-ended questions encouraging students to be reflective, and opportunities to receive feedback will be particularly suitable to higher education students.

Just as strategies to build in dialogue are structured into the unit design, approaches to build learner autonomy would also need to be well-thought-out and structured into the design plans. It would be helpful to make these strategies more transparent to learners by keeping the big-picture questions alive — 'where am I going', 'how am I getting there' and 'what next' — an approach to keep students' eyes on a current location, a route and a destination. A structure that visibly progresses the student, keeps motivation alive and fosters learner independence is especially valuable when learners are isolated from peers, the teacher and the on-campus learning environment and rich student experience.

Learner autonomy: Learner autonomy is critical in reducing the transactional distance ${ }^{22}$ and the remoteness of online delivery. Class activities, assignments and opportunities for interaction were built into the units so that learners could work independently and successfully and reduce the remoteness [ie the transactional distance]. Although most students were comfortable using Zoom and adapted to the online and remote delivery well, some participants ran an induction session prior to commencing the unit to make students comfortable and familiar with the technology which in turn was useful to build learner-independence, confidence and self-assurance. '...they knew how to access zoom, to test their cameras and microphones and avoid any technical issues' (Participant 1).

However, the reported increase in email queries seeking clarifications might be inferred as low learner autonomy, which may be attributed to the students being first year students in their first semester at university. Obviously, further work to foster learner autonomy and greater independence is necessary. Identifying areas where students can work independently and areas where they need support, including the type of support, will be helpful in going forward. Building their skills in areas such as time management, embedding multiple opportunities for feedback to improve independent learning, progress indicators in the form of formative tasks that develop students' ability to make evaluative judgments and monitor their own performance are all useful in building learner autonomy.

Overall, the findings have underscored the need to carefully balance the dialogue-structure-learner autonomy elements with a strong focus on the learner cohort and their context (in this instance the isolated remote learning context precipitated by the COVID-19 global pandemic). As one participant aptly summarised, "[the] First block delivered was stressful as [we] learnt on the run and [there is] no substitute for experience' (Participant 2).

22 Michael G Moore (n17) 666. 


\section{CONCLUSION}

Using a SWOT approach to categorise and interrogate the data overlaid with Moore's transactional distance theory as the analytical lens, this study has provided opportunities to reflect on remote teaching during a pandemic via intensive Block mode and highlighted key areas needing attention.

The critical importance of fostering dialogue and connection, purposefully structuring learning environments and learning designs that nurture independent, autonomous learners have been highlighted in this study. These study findings are useful prompts to modify teaching practices for a post-COVID future, especially in identifying practical strategies that maintain dialogue and build connection with students, creating structured learning environments that scaffold learners towards success and foster independent, autonomous learners. These ideas are applicable beyond law teaching and beyond first year at university. The pandemic forced all learners to be independent and self-directed, and conjecturing that remote learning may be here to stay, building learner independence and learner autonomy will be increasingly critical to all tertiary disciplines.

Intentionally designing learning structures that promote ownership and learner agency through working with learners' own experiences, tasks that build confidence by balancing responsibility, pedagogical complexity and challenge will be considerations for future remote learning curricular. Purposeful strategies and activities that promote greater engagement with other learners, classroom dialogues that foster a sense of community and opportunities to collaborate in small groups to learn from each other must complement all learning structures for remote learning.

There is now a growing range of tools that can be integrated with other existing and new technologies allowing academics to connect and conduct higher education learning and teaching in new and varied ways. The observation that "never have we had more tools at our disposal, particularly in the form of technology' 23 is perhaps the greatest opportunity in a post-COVID future. The participants' LMS and pandemic teaching complemented with synchronous Zoom sessions exemplifies this statement. The challenge ahead is to draw on the lessons learned, and plan future pedagogical interventions based on these realisations.

23 Chris Ashford, 'Law Teaching and the Coronavirus Pandemic' (2020) 54(2) The Law Teacher 167, 168. 